\title{
THE EARLY IMPACT OF COVID-19 PANDEMIC ON THE AVIATION INDUSTRY
}

\author{
Dávid MELAS*, Katarína MELASOVÁ \\ Technical University of Kosice, Faculty of Aeronautics, Rampova 7, 04121 Kosice \\ *Corresponding author. E-mail: david.melas@student.tuke.sk
}

\begin{abstract}
The goal of the paper is to assess early economics impact of Covid-19 on the aviation industry as it is one of the hardest hit industries. Covid-19 has an unprecedented impact on the international passenger seat capacity and gross passenger operating revenues of airlines. In the first part, we look at the impact of the pandemic on the economy as a whole and subsequently look at the economic cost of airlines. Two main elements are driving this negative trend - travel restrictions and overall economic development. We are currently experiencing the tightest international travel restrictions in the modern era of flight transportation with the economies worldwide experiencing a greater decline in GDP than during the last 3 recessions. In the second part, we look at two out of many possible path scenarios which are likely to drive the trend: V-shaped path and U-shaped path. All pandemic outbreaks before followed V-shaped scenario but Covid-19 has paralysed the society for longer with stricter governmental measures and so U-shaped scenario has to be taken into account as the most likely outcome for the aviation industry during this pandemic.
\end{abstract}

Keywords: Aviation industry; Covid-19; pandemic; U-shaped path

\section{INTRODUCTION}

Today, we see the impact of Covid-19 is having gradual effects like major economic depression comparable with the Financial crisis of 2007-08. Countries hit by a virus (unexpected and sudden disease) do experience a drop in overall economic activities and it subsequently spills on businesses. The contraction of the economy would begin with the diminishing of the travel and tourism sectors that hit all the airlines around the globe. Nevertheless, the pandemic has spiral effects on the national and global economy and it would be very ambiguous to estimate the economic costs from such a pandemic. In economic terms, any economic shock to one country is quickly spread to other countries through the increased trade and financial linkages associated with globalisation [1]. The United Nations Conference on Trade and Development (UNCTAD) has announced that the estimated cost to the global economy would be at least $\$ 2$ trillion in 2020 [2]. All these predictions directly transfer to the aviation industry as airlines across the world have grounded aircrafts as passenger number collapsed and governments have closed down the borders and international travel. Aviation is arguably one of the safest modes of transport in the world per number of people transported as stated by the International Civil Aviation Organisation (ICAO). Globally, and notwithstanding regional spikes, accidents became infrequent to the extent of becoming exceptional events and serious incidents became fewer and further apart [3]. However, there have been serious lay-offs in the industry with significant cuts still to come. For example, British Airways is set to cut up to 12,000 jobs from its 42,000-strong workforce, almost $30 \%$ cut, due to collapse of the business and needs for restructuring and redundancy programme [4].

In our article, we want to address the impact of the coronavirus known as "COVID-19" on the safest mode of transportation due to being one of the hardest hit industries. Our preliminary research will address the potential economic losses, setbacks and challenges faced by governments and airline operators worldwide Moreover, we aim to forecast possible short- and long-term effects of the pandemic on global air travel demand. We will also try to assess when we can expect the rebound to 
figures before the virus outbreak and the potential impact on the future of airlines. One has to understand that this is an unprecedented situation during the modern era of flight transportation as we have not experienced such a widespread impact of the virus, although we had SARS and MERS since early 2000 (but they were contained within regions and a small group of countries).

\section{AIRLINE ECONOMIC COST OF PANDEMIC}

In our case, we are interested in the economic impact of the current pandemic on tourism and airlines. According to the World Travel \& Tourism Council, tourism is a huge global business that accounts for $10.4 \%$ of global GDP and $10 \%$ of global employment. If we look on China, where the authorities agree the virus has originated from, Chinese tourists account for around $1 / 10^{\text {th }}$ of all cross boarders visitors and a huge drop in outbound tourism will have a significant impact and adverse shock in many countries as it can be seen in Europe or more specifically in Prague, the Czech Republic [5]. The World Tourism Organisation (UNWTO) has announced that the tourism sector is among hardest hit by a coronavirus and there is an expected fall in international tourist arrivals between 20 and $30 \%$ what could translate into a decline in international tourism receipts of between $\$ 300$ and 450 billion [6]. What is more interesting for our analysis is that the International Air Transport Association (IATA) estimates the airline cost as much as \$252 billion with approximate $44 \%$ drop in lost passenger revenues due to the collapse of the airline industry on 24 March 2020 [7].

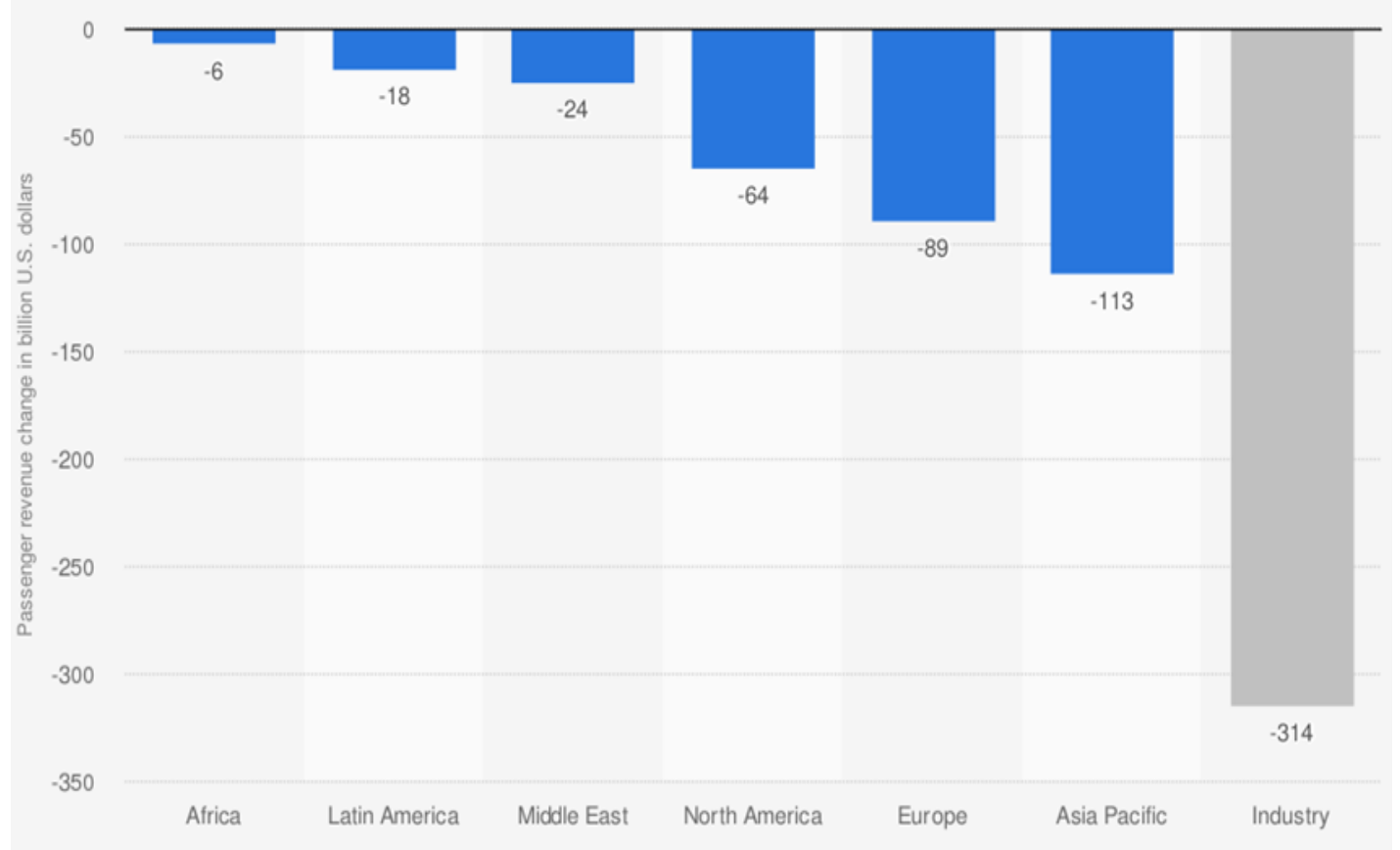

Figure 1. Airline passenger revenue change due to coronavirus outbreak worldwide in 2020, by region of airline registration (in billion U.S. dollars)

Source: ICAO, Statista.com

In this scenario, IATA expected and accounted for severe travel restrictions to last for three months. As the graph shows above shows, the IATA has released an updated analysis on 14 April 2020 showing that the COVID-19 crisis will see airline passenger revenues drop by $\$ 314$ billion in 2020, a 55\% decline compared to 2019 [8]. These updated figures accounted for a significant deepening of the crisis in the last three weeks and reflect predominantly three following parameters [9]:

- Severe domestic restrictions lasting three months 
- Some of these restrictions concerning international travel extending beyond the initial three months

- Worldwide severe impact, including Africa and Latin America which had a small presence of the disease and were expected to be less impacted in the March analysis.

Many governments worldwide had started to ease up the restrictions on socialising of people and are starting to open the shops, restaurants, hotels and social spaces such as gyms, libraries or events in phases. These would be a great impact on the local economy and would stimulate the demand for products and services which would, in turn, lead to diminishing negative impact of the predicted recession. However, governments will ease up travel restrictions last and it could increase the negative impact on airlines. Also, many people would be scare to take a flight as the spread of germs and viruses is higher in closed environments where people stay for hours such as planes. As IATA pointed out, the expected full-year passenger demand (domestic and international) likely to be down $48 \%$ compared to 2019 [8]. Two main elements are driving this change:

1. Travel restrictions - As mentioned above, travel restrictions have the greatest impact on air travel. Further travel restrictions will deepen the impact of the recession on demand for travel and the most severe impact is expected to hit second quarter (Q2) 2020, which are months April to June. As of early April, the number of flights globally was down $80 \%$ compared to 2019 with a predicted drop to $90 \%$ for the whole month of April by ICAO [10]. Depending on the scenario 1 or 2 -> V-shaped or U-shaped path, which we will discuss in-depth in next part of the paper, we can see the quicker or slower recovery when the governments will lift up severe travel restrictions which are hampering the demand. Domestic markets for air travel can be in the first stage of lifting travel restrictions and can lead to an upturn in demand starting in the Q3. However, this a small fraction of flights operated by the majority of airlines in Europe and the outlook for international markets are sluggish and will be slower to resume as governments appear to retain cross boarders travel restrictions for longer.

2. Overall economic development - According to early analysis of the crisis, we expected world GDP to contract by about $7 \%$ in the first half of the year 2020 which roughly the double the size of the contraction in 2009 during financial crisis [11]. The economic shock of COVID-19 is projected to be most severe in Q2 2020 when GDP is expected to fall by 6\%. Some sources such as Oxford Economics and European Investment Bank argue that there will be a rebound in economic activity in the second half of the year leading to GDP shrinking by $2.8 \%$ in 2020 overall, although more sceptic sources argue that if the second wave of the virus hit us in Q3/Q4 2020, GDP would shrink significantly more, up to $8 \%$ this year [12]. By comparison, during the financial crisis in 2009, the global GDP shrunk by (only) $1.1 \%$. However, the impact of reduced economic activity in Q2 alone is likely to result in an $8 \%$ fall in passenger demand in the third quarter (Q3) according to IATA [8].

\section{WHAT IS NEXT? U-SHAPED VS V-SHAPED PATH SCENARIO}

Currently, the overall severity and duration of the Covid-19 pandemic are still uncertain with many variables constantly changing daily. However, there are two indicative scenarios which are indicators of likely paths or consequential outcomes out of many other variable paths. One has to take into account that the actual path of the recovery will eventually depend on factors such as availability of government assistance, general economic conditions, consumer's confidence and the most importantly duration and magnitude of the outbreak and successful containment measures which could bring faster recovery for the airline industry. The ICAO has been scenario building and two out of many possible scenarios came up as the most relevant, so-called U-shaped path and V-shaped path. These two scenarios are developed to explore the potential short-term economic implications of the Covid-19 pandemic [10]. In the next steps, we will present the potential paths. So, V-shaped scenario is a normal 
shape for a recession, with a quick drop and a brief period of contraction followed by smooth recovery and positive growth. Previous local pandemics had a V-shaped impact on aviation and were back to normal within 7 months of the outbreak. The most significant pandemic to date to hit the aviation industry was SARS which resulted in an annual reduction of $8 \%$ in revenue passenger kilometres (RPKs) and $\$ 6$ billion in revenues for Asia/Pacific Airlines. As mentioned above, Covid-19 had already surpassed these numbers with a decline of $48 \%$ in RPKs and an estimated loss of $\$ 314$ billion in revenues. Asia/Pacific region is expected to lose $\$ 113$ billion which is almost 19 times more than during SARS outbreak.

As mentioned above, Covid-19 had already surpassed these numbers with a decline of $48 \%$ in RPKs and an estimated loss of $\$ 314$ billion in revenues. Asia/Pacific region is expected to lose $\$ 113$ billion which is almost 19 times more than during SARS outbreak. U-shaped path scenario is accounting for a prolonged period of contraction with muted recovery and the possibility of not returning to trend line growth by the end of October 2020, which is defined as a short-term outlook. Scenarios are predominantly differentiated in terms of demand and supply conditions. Demand condition is the degree of consumer confidence in air travel that can be translated into demand or socalled load factor, whereas supply conditions are mainly the timing and scale of airline capacity decline and recovery [13]. This decline in international passenger traffic is unprecedented and different organisations vary their estimated which range from a decline of 33\% to $74 \%$ in international passengers in 2020. The V-shaped scenario would indicate first signs of recovery in late May/early June with smooth capacity recovery to $75 \%$ of baseline level by September. There would still be a weak demand return. The U-shaped scenario indicates very slow recovery and progression of capacity to $40 \%$ of baseline level with limited, almost non-existent demand growth. Baseline level embodies the originally-planned, pre-pandemic trend line growth from 2019 level.

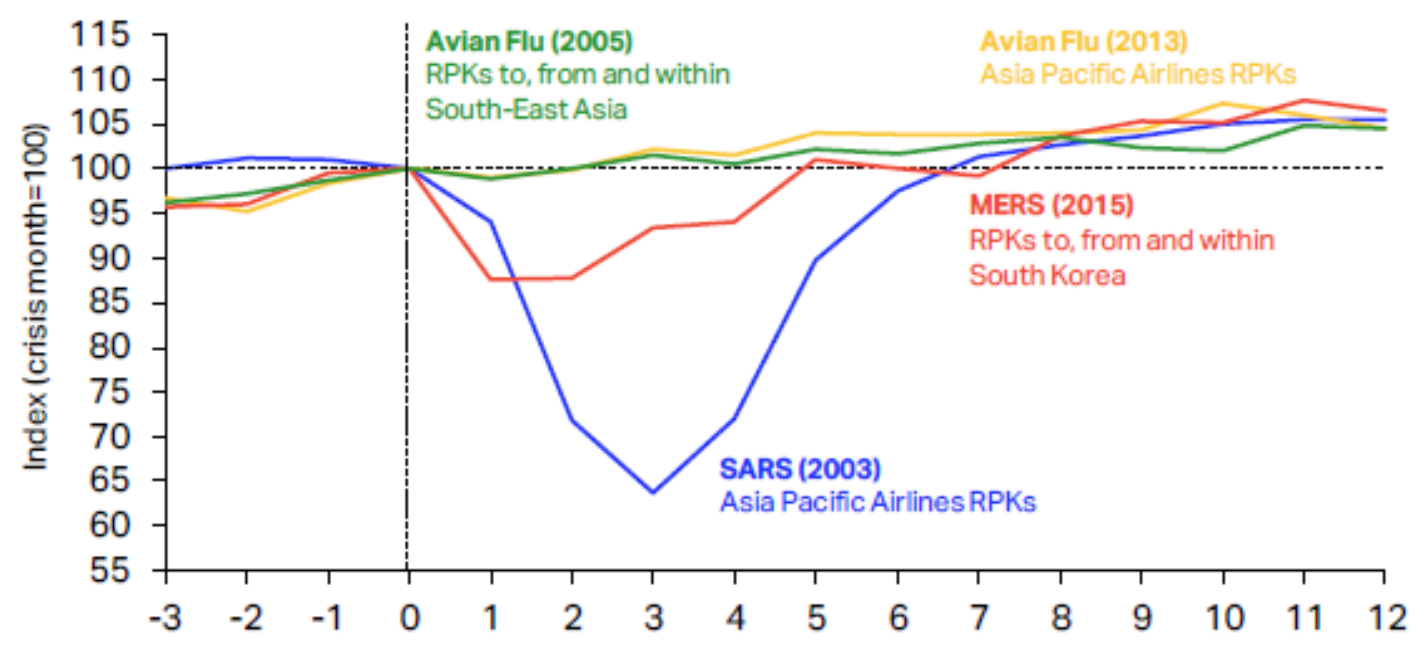

Months before and after the start of the crisis

Figure 2. Impact of past outbreaks on aviation Source: IATA Economics

\subsection{Impact on supply}

Impact on supply which is measured as International Passenger Seat Capacity is significant in both scenarios. Prior to the outbreak, airlines had planned to increase seat capacity by $4.2 \%$ for the first 9 months of 2020, compared to the same period of 2019 [10]. However, according to latest estimates and using our two scenarios, U-shaped path would lead to a more significant drop in passenger seat capacity by $57 \%$ to $67 \%$ when compared to $\mathrm{V}$-shaped path decline of $41 \%$ to $56 \%$. This capacity level is also projected, by similar percentages below the 2019 level. As seen from the above graph, the biggest capacity loss is expected in Asia/Pacific and Europe, followed by North America. The least affected should be Africa unless there would be a greater outbreak in the following weeks. 


\subsection{Impact on operating revenues}

Gross Passenger operating revenues of airlines were planned to increase by almost $\$ 15$ billion for the first 9 months compared to the same period of 2019. This has to take into account the predicted trend line growth of demand and planned seat capacity for the 2020 year. According to the latest estimates, airlines revenue would plummet significantly for U-shaped path scenario and would be between $\$ 203$ and $\$ 238$ billion which is predicting approximately $\$ 40$ billion greater loss than in the $\mathrm{V}$-shaped path scenario where the numbers are predicted between $\$ 145$ to $\$ 204$ billion. As before, more than two-thirds of the gross passenger operating revenue loss would be recorded by Europe and Asia/Pacific.

\subsection{Impact on airport industry}

One of the neglected parts of aviation infrastructure which do not get enough attention are major airports. They are the main hubs for all the international and most of the domestic flights. The early reports from Airports Council International (ACI) show that the airports worldwide are expected to lose almost half of the forecasted baseline revenue in a pre- COVID-19 scenario [14]. In other words, total airport revenues losses are expected to contract by around $\$ 77$ billion in 2020 .

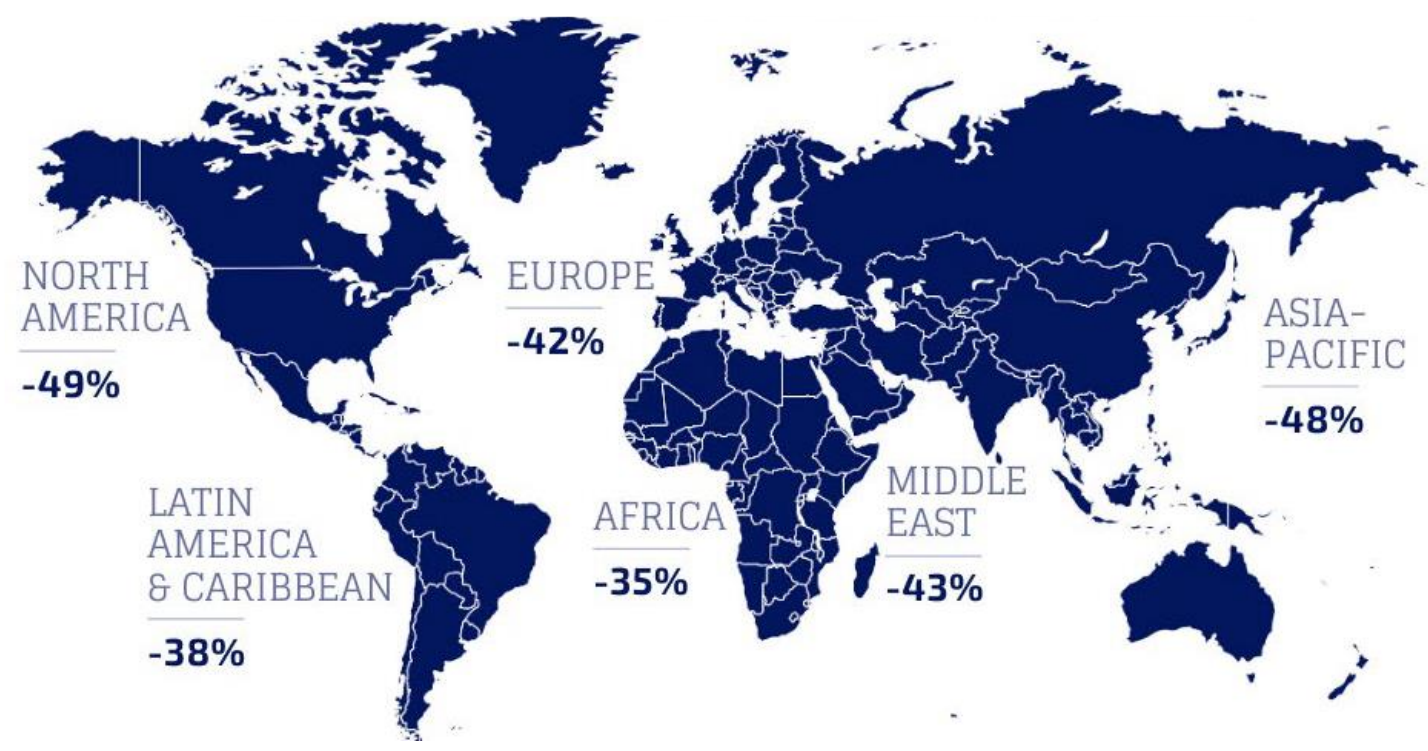

Figure 3. Estimated airport revenue losses for YE $2020^{1}$

Source: ACI Policy Brief

This is an existential challenge for most airport operators worldwide as the will not be able to recover the foregone costs in the future, mostly due to a slower expected return of customers following the U-shape path scenario. Such a financial shock and dramatic loss in revenue are mostly associated with direct loss in absolute volumes of traffic and fall in non-aeronautical revenues such as retail concessions, car parking or property rent. To put in perspective, retail concessions was the largest source of non-aeronautical revenue for airports at $30.2 \%$, car parking revenue was the second-largest source at $20.1 \%$ and property rent was third at $15 \%$ in 2017 [15]. Overall, aeronautical revenues account for 55.8\% of global airport's revenues and non-aeronautical for 39.9\% in 2017 [15]. This would also be a huge shock for employment as the personnel employed by airport operators directly and through third parties accounts for about $60 \%$ of total jobs in the aviation sector. There have to be

${ }^{1}$ Compared to Baseline (business as usual, originally-planned); revenues include both aeronautical and non-aeronautical. 
governmental policies in place to protect employment. Except for the most obvious support from the governments in the form of comprehensive financial relief package, there are few examples such as:

- Tax relief as taxes are a significant share of the airport's cost base

- Airport rents and concession fees can be waived by local governments to lower the fixed costs of airports

- Continuity of air cargo operators to bring some percentage of revenue and to keep essential cargo facilities open and staffed

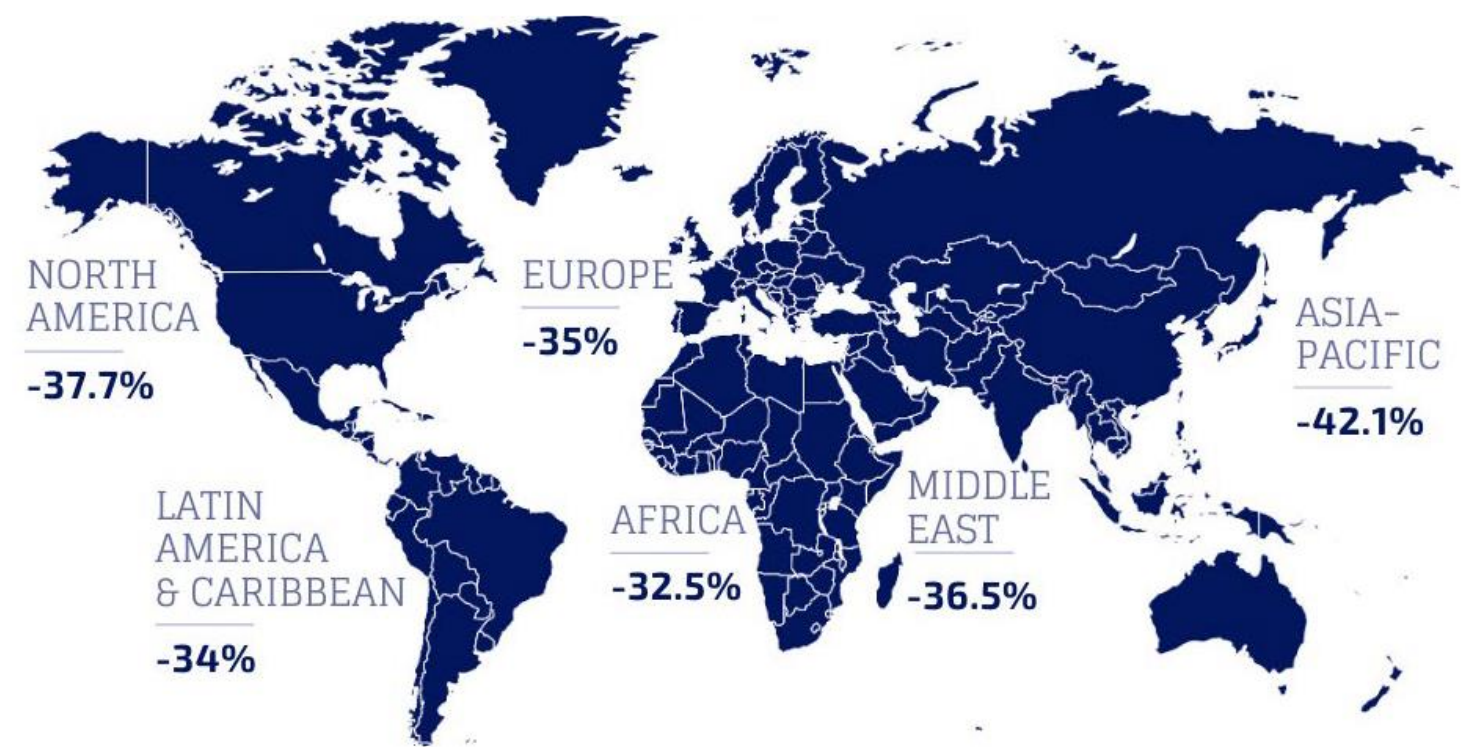

Figure 4. Estimated airport passenger traffic losses for YE $2020^{2}$

Source: ACI Policy Brief

\section{CONCLUSION}

The goal of this paper was to establish potential scenarios for the Covid-19 outbreak and its impact on the aviation industry - airlines and airports. We have outlined the two most likely paths of the impact on aviation with a potential impact on supply and operating revenues of airlines. These estimates are likely to change and either improve or worsen depending on the measures undertaken by the governments worldwide and their willingness to ease up travel restrictions concerning the aviation industry. Biggest driver will be the consumer's confidence regarding the safety measures in order to limit the spread of the virus during the travel. While previous pandemics such as SARS had V-shaped impact on aviation as shown on the figure 2, leading to a rather fast recovery, Covid-19 pandemics paralyses societies for much longer with stricter measures. This is likely to take the U-shaped path with greater impact on the aviation industry in the short-term. There is also a risk that we can experience $\mathrm{W}$-shaped scenario meaning there would be new regional peaks in the virus outbreak leading to prolonged negative consequences and locked borders in certain regions hitting major aircraft carriers and airports the hardest. Africa is given little consideration in the paper due to poor data delivery of local authorities but the pandemic is spreading very rapidly lately there.

However, not only international routes are severely hit but also domestic and regional air transport has been significantly impacted and shut down. The Covid-19 has the biggest impact on Asia/Pacific and Europe regions where the situation can worsen during the summer season if there will be limited opportunity to travel across countries. On the other hand, European governments start to ease up the restrictions and slowly, in phases, opening services and social spaces. This could have a positive impact on the aviation industry as they might be able to come strongly in the summer season and wipe

\footnotetext{
${ }^{2}$ Compared to Baseline (business as usual, originally-planned), airport passenger traffic includes both international and domestic.
} 
off some losses experienced from March to May. Lastly, in the paper, we did not discuss air freight as the picture is very differentiated. While overall tonnage went down 19\% last March due to the grounding of passenger jetliners leading to the withdrawal of lower deck transport capacity, cargo flown on board of freighters grew by 9\% compared to March 2019 [16].

In conclusion, the impact on the airlines is and will be very negative, the evidence on cargo transport is mixed and has rather a positive trend. On the other hand, the impact on airport operators will be significantly negative and they will have a harder time to recover the foregone revenue. Their fixed costs are much higher when compared to airlines and it can have a longer impact on employment due to slower recovery and a limited number of flights in the first weeks and months after the pandemic. It will be very interesting to see how the governments will react and whether the impact on the aviation industry will be as severe as outlined in this paper. There will be definitely a follow-up paper on this topic.

\section{References}

[1] Lee, J.W. - McKibbin, W.J. Globalization and Disease: The Case of SARS. Cambridge MA, USA: MIT Press. 2004.

[2] United Nations Conference on Trade and Development. The Coronavirus Shock: A Story of Another Global Crises Foretold and What Policymakers Should Be Doing About It. Geneva, Switzerland, 9 March 2020.

[3] International Civil Aviation Organisation. Safety Management Manual. $2^{\text {nd }}$ ed., ICAO Doc 9859, Montreal, Quebec, Canada, 2009. pp. 3-5.

[4] BBC. British Airways to cut up to 12,000 jobs as air travel collapses. London, United Kingdom, 2020, [online]. Website: https://www.bbc.com/news/business-52462660 [Accessed on 28 April 2020].

[5] Organisation for Economic Co-operation and Development. OECD Interim Economic Assessment - Coronavirus: The World Economy at Risk. Paris, France, 2 March 2020.

[6] World Tourism Organisation. News Release: International Tourist Arrivals Could Fall by 2030\% in 2020. Madrid, Spain 27 March 2020.

[7] Pierce B. Covid-19: Cash Burn Analysis. Montreal, Canada: IATA Publication, 31 March 2020.

[8] International Air Transport Association. Covid-19 Puts Over Half of 2020 Passenger Revenues at Risk. Press Release No. 29, Geneva, Switzerland, 14 April 2020.

[9] Pierce B. Covid-19: Updated Impact Assessment. IATA Publication, 14 April 2020.

[10] International Civil Aviation Organisation. Effects of Novel Coronavirus (COVID-19) on Civil Aviation: Economic Impact Analysis. Montreal, Canada: Air Transport Bureau, 28 April 2020.

[11] Oxford Economics. World Economic Prospects April 2020. Oxford, United Kingdom. 2020.

[12] European Investment Bank. COVID-19 Weekly Update - April 8, 2020. Luxembourg: IEB, 8 April 2020.

[13] International Civil Aviation Organisation. Analysis of Economic Impacts of COVID-19 Global and State-level, ICAO data, Montreal, Canada. 2020. Website: https://www.icao.int/ substainabilitz/Pages/Economic-Impacts-of-COVID-19.asspx [Accessed on 28 April 2020].

[14] Airports Council International. Policy Brief Covid-19: Relief Measures to Ensure the Survival of the Airport Industry. Montreal, Canada: ACI World. 2020.

[15] Holland J. ACI Report Illustrates 'Importance of Non-aeronautical Revenues for Airports' Financial Stability. Brentford, United Kingdom: The Moodle Davitt Report. 2019.

[16] Heiner S., ICAO Presents Sobering Aviation Scenarios. Hamburg, Germany, 19 April 2020. Received 12, 2019, accepted 07, 2020

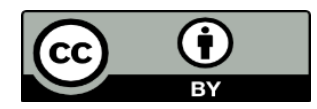

Article is licensed under a Creative Commons Attribution 4.0 International License 